\title{
Effects of lithium chloride illness on food preference in pigeons: A concurrent operants procedure for the study of food-aversion learning
}

\author{
WILLIAM BUSKIST \\ Auburn University, Auburn, Alabama \\ and \\ H. L. MILLER, JR. \\ Brigham Young University, Provo, Utah
}

\begin{abstract}
Food-aversion learning in pigeons was studied using a concurrent operants methodology. Twelve subjects received extensive baseline training consisting of exposure to a concurrent variableinterval 1-min variable-interval 1-min schedule of reinforcement. A different food, milo or peas, was associated with each schedule. Following the establishment of stable preferences, the birds were given exposure to one of the foods in their home cages. Immediately thereafter, the birds were injected with lithium chloride. For half of the birds, the dosage was $0.3 M$; for the other half, it was 0.6M. Within these groups, for half of the subjects, the injection followed ingestion of the preferred food; for the remaining subjects, it followed the nonpreferred food. Subsequently, the animals were again exposed to the operant choice procedure, and alterations in food preference were assessed. In general, postinjection shifts in preference were greater for birds that received the $0.6 \mathrm{M}$ dosage. In all cases, preinjection levels of preference eventually reappeared. In addition to the effects on food preference, lithium toxicosis also tended to suppress animals' overall rates of keypecking. Taken together, these results support the potential applicability of a concurrent operants methodology to the study of food-aversion learning.
\end{abstract}

Food-aversion learning has been studied in a variety of animals, including rats, quail, pigeons, coyotes, and humans (for a review, see Barker, Best, \& Domjan, 1977). Regardless of the species under study, however, the experimental procedure is generally the same: Subjects are exposed to a classical procedure involving the forward pairing of a food or liquid with an illnessproducing event, such as intraperitoneal (i.p.) injections of lithium chloride $(\mathrm{LiCl})$ or $\mathrm{x}$-irradiation, and then later exposed to the same food or liquid. The amount of food consumed by experimental subjects is then compared to that consumed by control animals that experienced the same sequence of experimental events except the illnessproducing event. Food aversion is demonstrated if experimental animals consume relatively less food than control animals during the postpoisoning period.

The simplicity of this procedure has led to extensive parametric replications. For example, researchers have examined the delay between food consumption and subsequent illness (e.g., Kalat \& Rozin, 1973), the type and level of illness-inducing agents (e.g., Nachman \& Ashe,

Reprints may be obtained from William Buskist, Department of Psychology, Auburn University, Auburn, AL 36849.
1973; Nachman \& Hartley, 1975), the familiarity/novelty of the food paired with poison (e.g., Domjan \& Gillan, 1976), the salience of visual versus gustatory cues (e.g., Wilcoxon, Dragoin, \& Kral, 1971), and so forth. This body of research has yielded a fairly consistent, coherent account of the ways in which animals select or avoid foods (e.g., Garcia \& Hankins, 1977).

Several recent studies have shown that stimuli paired with illness-producing events can suppress schedulecontrolled behavior. For example, when water was served as the reinforcer, responding on a single schedule of reinforcement decreased when injections of d-amphetamine (D'Mello \& Stolerman, 1978; Stolerman \& D'Mello, 1978) or lithium chloride (Logue, 1980) followed drinking. Similar results have been reported for animals responding on single schedules of reinforcement for food (Glowa \& Barrett, 1983). In the present experiment, pigeons chose between two different foods according to a concurrent variable-interval variable-interval (VI VI) schedule of reinforcement. A different food was associated with each VI schedule. After stable preferences were established, each bird received an IP injection of lithium chloride that was paired with one of the two foods. Food preferences were then monitored over the next several days using the same concurrent VI VI procedure. 


\section{METHOD}

\section{Subjects}

Twelve male White Carneaux pigeons, maintained at $80 \%$ of their free-feeding weights, served as subjects. The birds had no previous experience in food-aversion experiments but had been exposed to several concurrent VI VI schedules of reinforcement. Each subject had free access to grit and water in its home cage. Birds were given 10-20 g of mixed grain following experimental sessions, except on those days when injections were administered.

\section{Apparatus}

A three-key, three-hopper pigeon chamber was used. The interior of the chamber measured $34 \times 38 \times 35.5 \mathrm{~cm}$. The center key and hopper were inoperative. The two side keys were located $24 \mathrm{~cm}$ above the floor, $6.5 \mathrm{~cm}$ from each other, and $7.5 \mathrm{~cm}$ from the side walls. Hopper apertures $(5 \times 5 \mathrm{~cm})$ were located $12.7 \mathrm{~cm}$ directly below each key. During each session, the left key was illuminated with red light, the left hopper contained milo, the right key was illuminated with green light, and the right hopper contained Austrian winter peas. A 9.6-W houselight was illuminated during each session. The keylights and the houselight were darkened during the 3-sec activation of the hopper. An exhaust fan was used to mask extraneous noise. Recording of data and the scheduling of intrasession events were performed using a DEC PDP-8e minicomputer equipped with the SUPERSKED software system.

\section{PREFERRED}

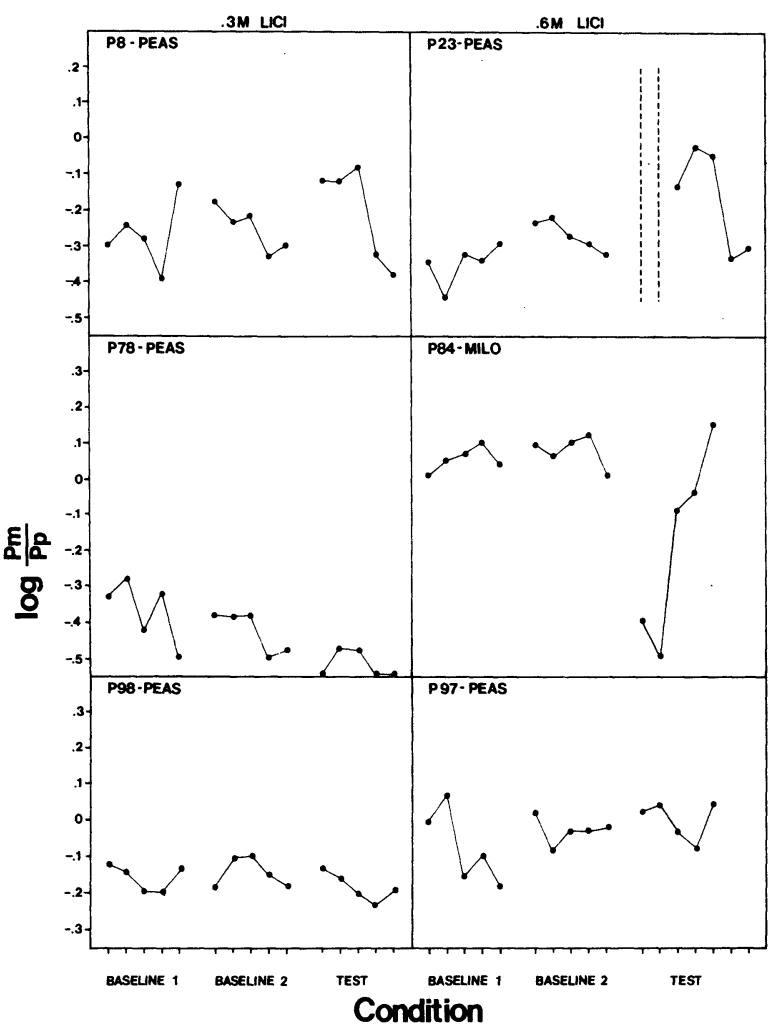

Figure 1a. Logarithms of the ratio of responses for milo to responses for peas are shown for each bird in the two groups where LiCl $(0.3 M$ and $0.6 M)$ was paired with the preferred food. The dashed lines for Bird P23 represent sessions in which the animal failed to peck either key. For each bird, the food paired with the $\mathrm{LiCl}$ injection is indicated in the upper left-hand corner of the panel.

\section{Procedure}

For the first 30 days of the experiment or until responding had stabilized (Condition 1), birds were exposed to a concurrent VI 1-min VI 1 -min schedule. Stability was defined as less than $10 \%$ variation in a sliding geometric mean over 5 consecutive days. On a given day after responding had stabilized, 6 birds were given $15 \mathrm{~g}$ of their preferred food in the home cage. The other 6 subjects were fed $15 \mathrm{~g}$ of their nonpreferred food. This procedure was used as a control for the subsequent effect of feeding birds in their home cages prior to $\mathrm{LiCl}$ injections (i.e., it provided an indication of the degree to which skipping an experimental session and being fed in the home cage would affect responding in the subsequent day's session). Over the next 5 days (Condition 2), birds were placed in the operant chamber and, as before, were given the choice between milo and peas on the concurrent VI 1-min VI 1-min schedule.

On the following day, each bird was again fed $15 \mathrm{~g}$ of either milo or peas in its home cage (birds were fed the same food during both homecage feedings). Immediately after feeding had ended, subjects in each group were administered IP injections of either $0.3 \mathrm{M} \mathrm{LiCl}$ or $0.6 \mathrm{M}$ $\mathrm{LiCl}$ (per liter of physiological saline, $1 \mathrm{ml} / \mathrm{kg}$ body weight). Thus, for half the birds, the injection followed the preferred food; for the remaining half, the injection followed the nonpreferred food. Moreover, half the subjects received the $0.3 \mathrm{M}$ dosage and half the $0.6 \mathrm{M}$ dosage.

Birds were next exposed to the milo-peas choice for five additional sessions (Condition 3). Birds that did not respond on the first day following injection (P67 and P100) or for 2 consecutive days (P23) were not given any supplemental food between experimental sessions.

\section{NONPREFERRED}

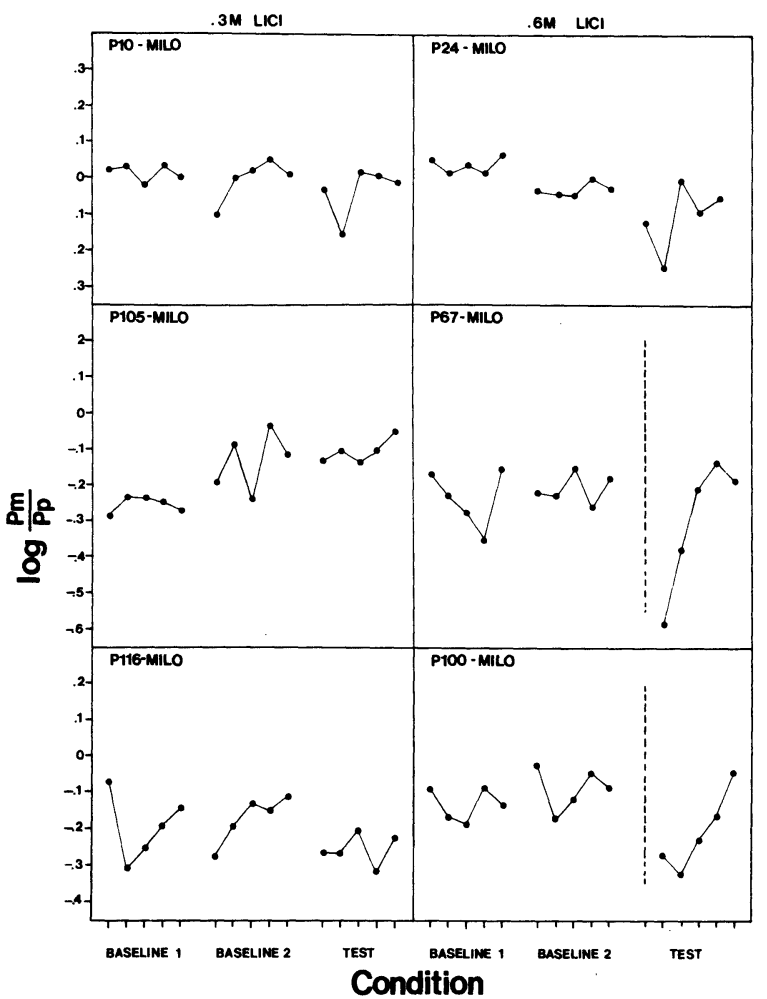

Figure 1b. Logarithms of the ratio of responses for milo to responses for peas are shown for each bird in the two groups where LiCl $(0.3 \mathrm{M}$ and $0.6 \mathrm{M})$ was paired with the nonpreferred food. The dashed lines for Birds P67 and P100 represent sessions in which they failed to peck either key. For each bird, the food paired with the LiCl injection is indicated in the upper left-hand corner of the panel. 
Birds were run daily, 7 days a week. On the 2 days in which birds were fed in their home cages, they were given the food at the time their sessions would have normally commenced. All sessions terminated after 30 reinforcements or $70 \mathrm{~min}$, whichever came first.

\section{RESULTS AND DISCUSSION}

Figure la shows the logarithm of the ratio of responses for milo to responses for peas during all experimental conditions for each bird that received an $\mathrm{LiCl}$ injection after consuming the preferred food. Figure $1 \mathrm{~b}$ shows similar data for birds that were injected following consumption of the nonpreferred food. The condition indicated as "Baseline 1" represents the five sessions immediately preceding the first feeding in the home cage. The "Baseline 2" condition refers to the five sessions prior to injection, and "Test" refers to the five sessions thereafter. A vertical dashed line represents a session in which no keypecking occurred. In both graphs, data from birds receiving $0.3 \mathrm{M}$ $\mathrm{LiCl}$ are displayed in the left panel, and data from those that received $0.6 \mathrm{M} \mathrm{LiCl}$ are shown in the right.

Preference for milo during each experimental condition is indicated by data points above the 0.0 value on the $y$-axis, and preference for peas is indicated by data points below this value. Thus, if poisoning altered birds' food preferences, shifts in response ratios should have occurred as follows: For birds that received the $\mathrm{LiCl}$ injection after eating milo, the value of the response ratio should have decreased; for birds that received the $\mathrm{LiCl}$ injection after eating peas, the value of the response ratio should have increased. The food paired with the $\mathrm{LiCl}$ injection is indicated in the upper left corner of each bird's graph.

The birds that received the $0.3 \mathrm{M}$ injection showed relatively little alteration in their food preferences. Bird P8 (see Figure 1a) was the only animal in the $0.3 \mathrm{M}$ preferredfood group to show a decrease in responding to the key associated with the preferred food following the injection, as indicated by the increased ratios of responding observed during the first 3 days of the test condition. The other 2 subjects (P78 and P98) in this group, as well as the 3 birds in the $0.3 \mathrm{M}$ nonpreferred-food group, showed virtually no change in preference. For the animals that received the $0.6 \mathrm{M} \mathrm{LiCl}$ injection, the results were quite different: 5 out of the 6 birds showed substantial but temporary changes in preference following the injection. Bird P23 (Figure 1a) did not keypeck or consume food during the first 2 days after receiving the $\mathrm{LiCl}$ injection. On the third day, this bird showed an initial decrease in responding to the key associated with peas, but by the sixth

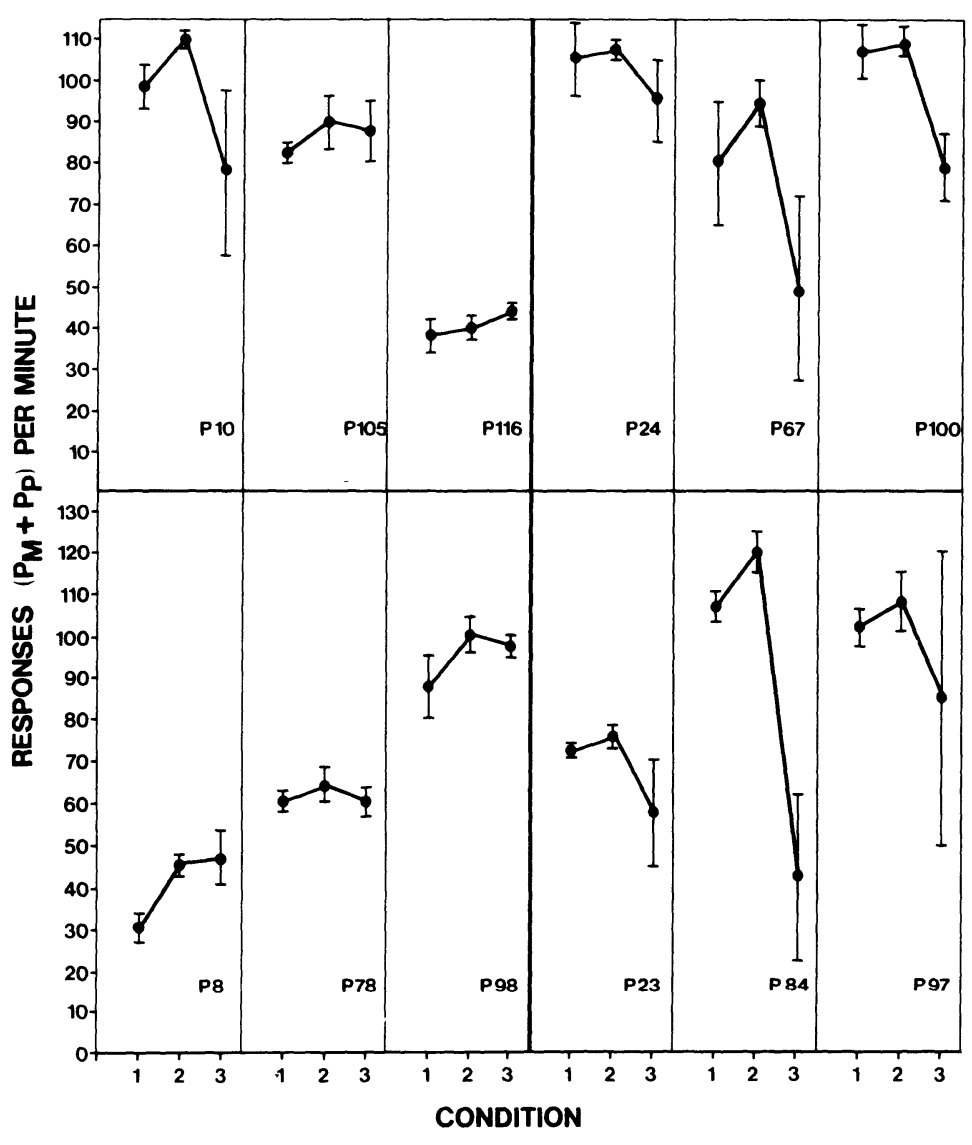

Figure 2. Total response rates are shown for each subject in the experiment. Data points represent arithmetic means over the last five sessions in each condition. Vertical brackets represent standard deviations. 
postinjection session it was displaying its original preference. The postinjection shift in preference was more pronounced for Bird P84. Only Bird P97 failed to show any alteration in preference.

Two birds (P67 and P100) in the nonpreferred-food group that received the $0.6 \mathrm{M} \mathrm{LiCl}$ injection failed to respond during the first postinjection session. However, in the subsequent sessions, the course of recovery of the original preference for these birds was similar to that displayed by the third bird (P23) in the group.

Figure 2 depicts the mean overall response rates across each condition for each bird. Data from the birds that received $0.3 M \mathrm{LiCl}$ after eating the nonpreferred food appear in the three upper left panels, whereas those from the $0.6 M \mathrm{LiCl}$, nonpreferred-food group are shown in the upper right panels. Data from the animals in the two groups whose injections followed the preferred food are shown in the lower panels. Also shown are the standard deviations of the response rates over the last five sessions in each condition. Overall, the subjects increased responding during Condition 2 and decreased responding in Condition 3. This decrease was often substantial for the birds that received $0.6 \mathrm{M} \mathrm{LiCl}$ injections.

Two aspects of the present procedure deserve special mention. First, the present experiment did not involve an explicit control group by which to assess the effects of the injection of the drug vehicle (i.e., a saline-only control group). However, 5 of the $0.3 M$ birds showed no changes in food preference, and the remaining bird in that group showed only a small change in preference following the injection. This observation strongly supports the notion that the changes in food preference that were exhibited by the $0.6 \mathrm{M}$ birds following injections were due to $\mathrm{LiCl}$ illness and not to the drug vehicle. In addition, 3 of the $50.6 \mathrm{M}$ birds that showed a change in food preference following injection also failed to peck either key during the first (P67 and P100) or the first and second (P23) days of the test condition, suggesting a considerable effect of illness. These subjects' failure to keypeck was accompanied by a failure to eat in the home cage as well. Under this heightened condition of deprivation, it may be reasonable to expect a dampening of food preference. However, once responding was resumed, marked preferences were exhibited, again suggesting the effects of the illness were specific to a particular food.

Taken together, the results show a temporary, dosedependent food aversion in pigeons when food preference was measured using a concurrent operants procedure. Moreover, the effect occurred regardless of whether the injection was paired with ingestion of the preferred or nonpreferred food. Furthermore, for most birds, shifts in preference following illness were accompanied by an overall decrease in responding, indicating a possible aversion to both foods. That these results are consistent with the existing literature on food-aversion learning in general and on food-aversion learning in avians in particular (e.g., Brett, Hankins, \& Garcia, 1976; Wilcoxon et al., 1971) supports the potential utility of the concurrent operants methodology in an area of research where it has been traditionally neglected.

\section{REFERENCES}

BARKer, L. M., Best, M. R., \& Domuan, M. (Eds.). (1977). Learning mechanisms in food selection. Waco, TX: Baylor University Press. BreTT, L. P., HankINs, W. G., \& Garcia, J. (1976). Prey-lithium aversions: III. Buteo hawks. Behavioral Biology, 17, 87-98.

D'Mello, G., \& Stolerman, I. P. (1978). Suppression of fixed-interval responding by flavour amphetamine pairings in rats. Pharmacology, Biochemistry, \& Behavior, 9, 395-398.

Domuan, M., \& GillaN, D. (1976). Role of novelty in the aversion for increasingly concentrated saccharin solutions. Physiology \& Behavior, 16, 537-542.

Garcia, J., \& HANkINS, W. G. (1977). On the origin of food aversion paradigms. In L. M. Barker, M. R. Best, \& M. Domjan (Eds.), Learning mechanisms in food selection (pp. 3-22). Waco, TX: Baylor University Press.

GLOWA, J. R., \& BARRETT, J. E. (1983). Response suppression by visual stimuli paired with postsession d-amphetamine injections in the pigeon. Journal of the Experimental Analysis of Behavior, 39, 165-173.

Kalat, J. W., \& RoZIN, P. (1973). "Learned safety"' as a mechanism in long-delay taste-aversion learning in rats. Journal of Comparative \& Physiological Psychology, 83, 198-207.

LOGUE, A. W. (1980). Visual cues for illness-induced aversions in the pigeon. Behavioral \& Neural Biology, 28, 372-377.

NaCHMAN, M., \& AsHE, J. H. (1973). Learned taste aversions in rats as a function of dosage concentration and route of administration of LiCl. Journal of Comparative \& Physiological Psychology, 10, 73-78.

NACHMAN, M., \& HARTLEY, P. L. (1975). The role of illness in producing learned taste aversion in rats: A comparison of several rodenticides. Journal of Comparative \& Physiological Psychology, 89, 1010-1018.

Stolerman, I. P., \& D'Mrllo, G. D. (1978). Amphetamine-induced taste aversion demonstrated with operant behavior. Pharmacology, Biochemistry \& Behavior, 8, 107-111.

Wilcoxon, H. C., Dragoin, W. B., \& Kral, P. A. (1971). Illnessinduced aversions in rat and quail: Relative salience of visual and gustatory cues. Science, 171, 826-828.

(Manuscript received for publication March 2, 1987.) 